\title{
0 diretor enquanto gestor e as diferentes pressões e dilemas da prestação de contas na escola pública
}

\section{The director as manager and the different pressures and dilemas of answerability in the state public school}

\section{El director como gestor y las diferentes pressiones y dilemas de la rendición de cuentas en la escuela pública}

\begin{abstract}
Almerindo Janela Afonso'
Universidade do Minho, Portugal, Professor Associado do Departamento de Ciências Sociais da Educação; Pesquisador do Centro de Investigação em Educação (CIEd)
\end{abstract}

Resumo: Em Portugal, as escolas públicas dos ensinos básico e secundário e os jardins de infância públicos foram, na sua maioria, integrados nos designados Agrupamentos de Escolas. Cada um desses agrupamentos, bem como as escolas que não foram integradas, regem-se por um modelo de administração no qual se sobressaem dois órgãos fundamentais: o Diretor, que é o órgão (unipessoal) de gestão, e o Conselho Geral, que é o órgão (colegial) de direção. Nesse último órgão participam os representantes de diferentes atores e interesses da Comunidade Educativa (internos e externos). Diretor presta contas pelas suas decisões, quer ao Conselho Geral, quer, sobretudo, ao Ministério da Educação e outros serviços da burocracia do Estado com poder fiscalizador e hierárquico. Mas não apenas. Com efeito, em um contexto em que também é crescente o escrutínio ou controle das famílias e dos stakeholders sobre as escolas e agrupamentos de escolas, sobretudo em relação a resultados acadêmicos mensuráveis, as pressões que se exercem sobre o diretor colocam-no, ainda mais, perante formas diferenciadas (e, não raras vezes, contraditórias) de accountability (isto é, processos ambivalentes e heterogêneos de avaliação, prestação de contas e responsabilização). $\bigcirc$ foco neste artigo, no entanto, incide no pilar da prestação de contas.

Palavras-chave: Gestão escolar. Diretor. Gerencialismo. Prestação de contas.

Doutor e Mestre em Sociologia da Educação pela Universidade do Minho, Portugal. 
Abstract: In Portugal, public elementary and secondary schools and public kindergartens were mostly integrated into the so-called School Groupings. Each of these school grouping, as well as the schools that were not integrated, are governed by a model of administration in which two fundamental bodies stand out: The Director, who is the management body, and the General Council, which is the collegiate body of direction. The Director is accountable for his decisions to the General Council and above all to the Ministry of Education and other departments of the State bureaucracy, with supervisory and hierarchical power. But not only. Indeed, in a context where there is also increasing scrutiny or control of families and stakeholders on schools and school grouping, especially in relation to measurable academic results, the pressures exerted on the director place him even more in the face of differentiated (and not infrequently contradictory) forms of accountability (i.e., ambivalent and heterogeneous processes of evaluation, answerability, and responsibilization). This article, however, focuses mainly on the pillar of answerability.

Keywords: School management. Director. Managerialism. Answerability.

Resumen: En Portugal, las escuelas públicas de la enseñanza no superior y jardines de infancia públicos se han integrado, en su mayoría, en agrupamientos escolares. Cada uno de estos agrupamientos, así como las escuelas que no fueron integradas, se rigen por un modelo de administración donde sobresalen dos órganos fundamentales: el Director, que es el órgano (unipersonal) de gestión, y el Consejo General, que es el órgano (colegial) de dirección. En este último órgano participan los representantes de diferentes actores e intereses de la Comunidad Educativa (internos y externos). El Director rendirá cuentas por sus decisiones, tanto al Consejo General, así como, sobre todo, al Ministerio de Educación y otros servicios de la burocracia del Estado, con poder fiscalizador y jerárquico. Pero no sólo. En efecto, en un contexto en que también es creciente el escrutinio o control de las familias y de los stakeholders sobre las escuelas y agrupamientos de escuelas, sobre todo en relación a resultados académicos mensurables, las presiones que se ejercen sobre el director lo sitúan, aún más, ante formas diferenciadas (y no raras veces contradictorias) de accountability (es decir, procesos ambivalentes y heterogéneos de evaluación, rendición de cuentas y responsabilización). El enfoque de este artículo, sin embargo, se centra principalmente en el pilar de la rendición de cuentas.

Palabras clave: Gestión escolar. Director. Gerencialismo. Rendición de cuentas. 


\title{
1 INTRODUÇÃO
}

$\bigcirc$ texto que a seguir se desenvolve se inscreve na continuidade de outros trabalhos do autor (por exemplo, AFONSO, 2003, 2010), recorrendo, uma vez mais, a contributos de pesquisa que, genericamente, podem ser referenciados quer à sociologia das políticas de educação, quer à sociologia das organizações educativas. ${ }^{2} \bigcirc$ foco, neste caso, é a figura do gestor (oficialmente designado diretor), o qual tem vindo a adquirir uma crescente (e contraditória) centralidade no atual "regime de autonomia, administração e gestão" das centenas de Agrupamentos que integram a grande maioria das escolas públicas portuguesas dos ensinos básico e secundário (fundamental e médio) e estabelecimentos de educação pré-escolar.

A abordagem que aqui se privilegia procura acrescentar mais alguns argumentos a uma linha de pesquisa sobre accountability em educação, tendo, neste caso, como motivação a publicação recente de um trabalho realizado pelo Instituto de Ciências Sociais da Universidade de Lisboa e financiado pela Fundação Calouste Gulbenkian que inclui nas conclusões, entre outras, uma afirmação que nos parece particularmente relevante e instigante pelo fato de chamar a atenção para as dificuldades encontradas na tarefa de "retratar o sistema educativo português", nomeadamente em relação à gestão. Segundo Almeida et al. (2017, p. 313), tratou-se de uma

\begin{abstract}
Tarefa complexa, porque a informação existente não está disponível de forma acessível e transparente; contida em diferentes bases de dados (quer estatísticas, quer legislativas), revela grande dispersão e opacidade [...] Paradoxalmente, este traço (estrutural?) do sistema educativo contraria, exemplarmente, quer a adesão proclamada pelo poder político à prestação de contas [...] quer a imposição às escolas públicas de instrumentos de clarificação permanente da sua ação, por parte da administração central.
\end{abstract}

\footnotetext{
2 Este trabalho é financiado pelo Centro de Investigação em Educação (CIEd), projetos UID/ CED/1661/2013 e UID/CED/1661/2016, Instituto de Educação, Universidade do Minho, por intermédio de fundos nacionais da FCT/MCTES-PT.
} 


\section{OS DIRETORES DE ESCOLA NA ENCRUZILHADA DE FORMAS DE ACCOUNTABILITY MÚLTIPLA}

A literatura especializada sugere que a accountability é uma questão problemática para os gestores públicos (BARZANÒ, 201 1), sobretudo quando sobre eles convergem demandas diferenciadas que podem ser constitutivas de uma intrincada "rede de accountability" ou, simplesmente, quando os gestores são confrontados com formas de "accountability múltipla" (SCHILLEMANS, 2015; POLLOCK; WINTON, 2016). ${ }^{3}$ Nesse sentido, e salvaguardando as especificidades organizacionais que aqui nos interessa considerar, a

accountability, no sentido de um conjunto de mecanismos,
formais e informais, que fazem com que as escolas
respondam perante diferentes públicos e parceiros
interessados nos resultados da educação, representa um
dos maiores desafios que as escolas - e os seus diretores,
em particular, - estão a enfrentar. (BARZANÓ, 2009, p. 28).

Por isso, é muito provável que os diretores das escolas públicas, enquanto gestores públicos, tenham uma constante preocupação (quando não obsessão) em atender às regulamentações legais, às exigências hierárquicas e às demandas sociais relativas aos processos de avaliação, prestação de contas e responsabilização (três pilares fundamentais da accountability) e se confrontem, em razão disso, com dilemas e tensões decorrentes das diversas pressões e expectativas, internas e externas, advindas de uma pluralidade de atores (individuais e coletivos).

Com efeito, se considerarmos a realidade portuguesa, os diretores da escola pública (gestores) não podem deixar de prestar contas e de justificar (em

\footnotetext{
3 Em relação às escolas norte-americanas, isto mesmo é sinalizado por Marks e Nance (2007, p. 4), quando escrevem: "Externally, multiple accountability contexts [...] have the potential to support or constrain the influence of school principals." Embora não se refiram à escola, não deixa de ser pertinente notar também a observação de Jantz e Jann (2013, p. 229): "The overall assumption in the growing literature about accountability is that the number of actors involved in accountability arrangements is rising, that accountability relationships are becoming more numerous and complex, and that these changes may lead to contradictory accountability relationships, and finally to 'multi accountability disorder'."
} 
circunstâncias e com prioridades diversas) as suas ações e opções, desde logo, ao ministério da tutela, inspeção da educação, tribunal de contas, autarquias e outros órgãos e departamentos da administração pública, bem como, de forma mais imediata, aos diferentes membros da comunidade educativa, nomeadamente aos seus representantes no Conselho Geral (com destaque para os professores, pais/encarregados de educação e aos próprios alunos). E, ainda, numa acepção mais ampla, a outros stakeholders, nos quais podem ser incluídos os partidos políticos, os sindicatos, os media e outras entidades com quem se estabelecem parcerias e protocolos de colaboração (câmaras municipais, comissões de proteção de crianças e jovens, empresas, igrejas, ONGs, associações profissionais ou de outra natureza, instituições privadas de solidariedade social, etc.) e, mais recentemente, fundações privadas filantrópicas (sobretudo as que se assumem como think tanks para a educação e que financiam projetos nessa área). ${ }^{4}$

Considerar assim a pluralidade contraditória de interesses, pressões e expectativas constitui um permanente desafio (também de mediação) que não se compadece com qualquer perfil de diretor (gestor). ${ }^{5}$ Muitas vezes ardilosamente construídas, as estratégias para lidar com essas tensões terão necessariamente de considerar, entre outros aspectos, a existência de diferentes modos de accountability (formais e informais) que ocorrem interna

\footnotetext{
4 No caso português, a presença dessas fundações e de outras organizações empresariais começa a fazer-se notar na educação, em geral, e na escola pública, em particular. Um dos exemplos é o think tank EDULOG da Fundação Belmiro de Azevedo. Outro exemplo é o da Associação de Empresários pela Inclusão Social (EPIS), que, entre outros objetivos, visa à introdução de boas práticas de gestão nas escolas públicas - práticas essas inspiradas, claro está, em processos de gestão privada e empresarial. Como sublinhou Lima (2014, p. 1079) a esse propósito, "A ascensão de uma pós-democracia nas escolas públicas [...] concede primazia ao mundo empresarial que é tomado como modelo a seguir - [...] perante uma representação de passividade e de não participação por parte dos atores escolares, uma fraca qualidade democrática da vida escolar, um desinvestimento em políticas igualitárias e redistributivas, uma incapacidade deliberada para limitar os interesses dos atores sociais mais poderosos, uma diabolização dos sindicatos, uma desvalorização, sem precedentes, do pensamento pedagógico, da pesquisa educacional e dos saberes profissionais dos professores." Sobre a presença emergente desses novos atores na realidade portuguesa, ver também Antunes (2015) ou, para uma análise comparada, Antunes e Peroni (2017). No caso do Brasil, o movimento Todos pela Educação é o exemplo paradigmático de como os empresários estão influenciando, ou mesmo determinando, a política educacional. Para alguns trabalhos recentes a esse propósito, ver, por exemplo, Martins (2016), Martins e Krawczyk (2018) e Peroni (2018).

5 Nesse sentido, como tem sido analisado em outras situações, "Principals are mediators between external accountabilities [...] and school practices." (KOYAMA, 2014, p. 283).
} 
e externamente, e a instabilidade dos mandatos para a educação cujas prioridades, no que diz respeito à escola pública, frequentemente se alteram consoante as conjunturas sociais e políticas. Também por isso, a gestão das escolas é, em grande medida, a gestão desses processos - o que implica, para uma melhor compreensão sociológica e organizacional das suas práticas, saber como os gestores lidam com a zona contenciosa (contentious zone) constituída pelas intersecções entre demandas internas e externas de accountability, quando se sabe que essas demandas são frequentemente difíceis (quando não impossíveis) de compatibilizar (KNAPP; FELDMAN, 2012). E se considerarmos que, sobretudo nas últimas décadas, a ideologia gerencialista dominante tem feito prevalecer uma accountability baseada em resultados mensuráveis (AFONSO, 2009), essencialmente voltada para o que poderíamos designar de mandato cognitivo-instrumental - condensado na esclarecedora expressão "aprender para ganhar, conhecer para competir" (LIMA, 2012) -, é facilmente compreensível que, mesmo sem objetivos suficientemente discutidos para a construção de compromissos transversais em torno de projetos educativos (ou político-pedagógicos) autonomamente diferenciadores, e com algum desencanto das classes médias em relação à escola pública, a ação dos diretores escolares (gestores) não possa, ainda assim, deixar de ser guiada pelas exigências que resultam da coexistência articulada entre a meritocracia tradicional, assente na crença na capacidade e esforço individuais dos alunos, como suposto critério de justiça na aquisição de bens materiais, simbólicos e posicionais, e a parentocracia (BROWN, 1990), que repôs a centralidade interferente dos pais na construção dos percursos e opções dos filhos. Tratase, mais propriamente, de uma neomeritocracia (AFONSO, 2017) fortemente identificada com a utilidade do que se ensina e do que se aprende, congruente com a hipervalorização dos projetos individuais, e muito em razão das pressões familiares, das supostas exigências de formação do capital humano e das lógicas do novo espírito do capitalismo. ${ }^{6}$

6 Como observam Boltanski e Chiapello (2002, p. 46), "El espíritu del capitalismo es, precisamente, este conjunto de creencias associadas al ordem capitalista que contribuyen a justificar dicho orden y a mantener, legitimándolos, los modos de acción y las disposiciones que son coherentes com él." 
Como interpretar, então, a ideia tão divulgada de que um dos vetores da nova gestão pública é o reconhecimento e valorização de uma maior autonomia dos gestores? ${ }^{7}$ No caso das escolas públicas portugueses (em que os responsáveis pela gestão foram e são até hoje professores), essa (suposta agora) maior autonomia do diretor (gestor) traduz essencialmente o relativo afastamento (induzido pela ideologia dominante) em relação ao corpo profissional docente (e respectiva identidade coletiva) e a assunção cada vez mais explícita de uma nova identidade gerencialista. ${ }^{8}$ Quase se poderia falar da atualização gradual e quotidiana do princípio taylorista entre os que mandam executar, os que executam e os que supervisionam a execução. Assim, a desprofissionalização do trabalho docente é, de algum modo, sincrônica com a profissionalização do trabalho do diretor (gestor), enquanto trabalho especializado distinto da docência e cada vez mais afastado das questões pedagógicas. E quando isso acontece, "A denegação da especificidade educativa e pedagógica da gestão educacional [...] cinde o ato de gestão do ato educativo, atribuindo a este a condição de simples objeto a ser gerido de acordo com padrões racionais que lhe são estranhos, mas a que deve submeter-se, sob risco de irracionalidade, ineficácia e ineficiência." (LIMA, 2018b, p. 135).9

\footnotetext{
7 Autonomia essa que também é questionada em discursos que estão nos antípodas da nova gestão pública. Por exemplo, para a Fenprof (a maior federação de sindicatos de professores portugueses), a concentração de poderes no diretor veio consagrar "uma espécie de autonomia do chefe, em detrimento da autonomia da escola." (MENDONÇA, 2009, p. 38).

8 Esse relativo afastamento do gestor (diretor) em relação à sua identidade primeira (como professor) parece também poder vir a se tornar muito mais acentuado caso a resposta às interrogações levantadas por Torres (2013, p. 74) se concretizem: "Numa altura em que tanto se fala, se escreve e se opina sobre a liderança, importa perguntar até que ponto ela efetivamente existe para além da mera reprodução das lógicas centrais? Mais, como gere o líder a pressão bipolar a que é diariamente submetido, de um lado, a sua total dependência do centro a quem deve prestar contas, de outro, a sua vinculação à identidade profissional e organizacional da escola que representa? [E a resposta da autora conclui:] $\bigcirc$ paradigma de escola que emerge das instâncias políticas de regulação poderá induzir o desenvolvimento de lideranças cada vez mais desapossadas de sentido estratégico e político e, neste sentido, mais reprodutivas da cultura escolar centralmente difundida."

9 Em grande medida convergente com essa perspectiva, já há alguns anos, Paro (2001, p. 60) punha em causa a formação tecnicista do dirigente escolar porque "esta concepção, no que se refere ao diretor escolar, insiste em propugnar por uma formação diferenciada para o ocupante deste posto como se todos os educadores escolares não devessem ser candidatos a uma eventual função diretiva na escola. [E acrescenta:] Ao mesmo tempo, ignora a especificidade, a complexidade e a importância do caráter político-pedagógico das funções exercidas pelo dirigente escolar, reduzindo-as ao tecnicismo presente nos chamados 'princípios e métodos' da administração empresarial capitalista."
} 
Recuando um pouco no tempo, a metamorfose de uma condição para outra pode ser ilustrada com um breve exemplo. Pelo menos no contexto da transição do anterior para o atual modelo de administração das escolas públicas portuguesas (há precisamente uma década), segundo Afonso (2009), os gestores escolares ainda utilizavam três estratégias (ambiguidade, negociação tácita e resistência passiva) para lidar com as tensões resultantes de duas lógicas de ação: a anterior, de natureza mais burocrático-profissional, e a então emergente, de natureza gerencialista. Era uma conjuntura em que os diretores escolares, ainda incapazes de se libertar totalmente da sua identidade profissional primeira, enquanto professores, tendiam essencialmente, mediante essas estratégias, a evitar, suavizar ou adiar decisões sobre questões controversas quando havia conflito de interesses entre os professores e a tutela ministerial (AFONSO, 2009, p. 17-18).

Hoje, pelo contrário, o que parece se verificar é um crescente distanciamento dos diretores escolares em relação aos professores (antigos pares), assumindo-se aqueles, sem ambiguidade, como detentores de novos poderes cuja legitimidade há muito era reclamada, e que se atualiza, também entre nós, por influência externa advinda da "revalorização neoliberal do direito a gerir." (AFONSO, 2003, p. 46). ${ }^{10}$ A emergência dos diretores como figuras centrais na vida das escolas públicas portuguesas está, assim, muito ligada à expansão da ideologia da nova gestão pública, e a valorização política e simbólica desses atores não é indiferente à criação do Conselho das Escolas, ${ }^{11}$ bem como à criação de organizações associativas que visam ao fortalecimento da referida (nova) identidade gerencialista. ${ }^{12}$

\footnotetext{
10 Para uma melhor contextualização da expressão the right to manage, ver, por exemplo, Clarke e Newman (1993) ou Newman e Clarke (2012).

11 Conselho das Escolas é um órgão consultivo do Ministério da Educação que, entre outras atribuições, representa os estabelecimentos públicos de educação e ensino, podendo "participar na definição da política educativa para a educação pré-escolar e os ensinos básico e secundário." (cf. Decreto Regulamentar n. 32, de 29 de março de 2007). Esse órgão, criado em um período de governação em que alguns discursos e medidas legislativas tiveram como efeito a desvalorização do trabalho dos professores, nomeadamente com a tentativa de impor novas hierarquias entre eles, tem sido o lugar privilegiado de consulta e interlocução entre os representantes dos diretores e o Ministério da Educação, secundarizando de algum modo os sindicatos de professores.

12 As organizações referidas são a Associação Nacional dos Dirigentes Escolares e a Associação Nacional de Diretores de Agrupamentos e Escolas Públicas.
} 
Trata-se, por isso, de uma história (inicial) muito diferente daquela que pode ser descrita em relação a outros países, como o Brasil, muito embora, hoje em dia, os diretores, enquanto gestores escolares, estejam, em diferentes contextos nacionais, em situações, em grande medida, idênticas porque claramente pressionados ou condicionados pelos princípios dessa nova gestão pública que definem ou reconfiguram as suas funções.

Embora a sua emergência (inicialmente muito hesitante e ambígua), como órgão de gestão unipessoal, tenha sido em Portugal relativamente tardia em face de outros países (AFONSO, 1995), visto que somente há uma década se generalizou nas escolas públicas a figura do diretor, este parece ter vindo para ficar. Tudo indica, portanto, que a gestão democrática, tão longamente apregoada, e que continua prevista na Constituição da República Portuguesa (artigo 77), vai permanecer arredada (ou adiada sine die) enquanto ideário político-pedagógico e também como arquitetura organizacional de viabilização dos direitos de participação plural na vida da escola e de possibilidade legítima de tomada de decisões em órgãos colegiais democraticamente eleitos. ${ }^{13}$

A esse propósito, em face dos velhos e novos obstáculos que impedem a realização de uma gestão mais avançada em termos democráticos e participativos, Lima (2018a) se interroga se a gestão das escolas como "endogoverno democrático" não seria já, para certos setores sociais e políticos, "considerada uma irracionalidade em termos de uma gestão moderna, profissional e altamente exigente, incompatível com a falta de competência técnica da liderança e com formas de participação dos não especialistas em gestão." E denuncia: "Ao invés, o direito de gerir por parte de gestores profissionais seria crucial, sendo depois avaliado em função do programa político estabelecido e dos resultados obtidos, comparados com os objetivos e os resultados contratualizados junto das autoridades políticas e de outros interessados

\footnotetext{
13 Para compreender a gestão democrática em Portugal, que vigorou como modelo de administração e gestão das escolas públicas entre 1976 e 1991, é muito importante ter em conta as especificidades das mudanças políticas e culturais democráticas que se seguiram à revolução dos cravos de 25 de abril de 1974. Numa análise comparada com o Brasil, podemos encontrar motivações e antecedentes semelhantes, por exemplo, no fato de a gestão democrática ter sido em ambos os casos induzida pelos processos de transição dos respectivos regimes políticos autoritários para a democracia. Há, no entanto, que se considerar as diferenças em termos de experiências e práticas e mesmo uma distinta apropriação de significados relativos à própria expressão gestão democrática.
} 
(stakeholders), aí se incluindo, por exemplo, as famílias dos alunos." (LIMA, 2018a, p. 16, 24).

Apesar das especificidades nacionais, encontramo-nos, uma vez mais, tanto em Portugal quanto no Brasil, perante retrocessos semelhantes. Como refere Hypolito (201 1, p. 72),

Muitos dos avanços nas lutas por uma gestão democrática foram absorvidos e incorporados no discurso gerencialista que assola as escolas públicas. Conselhos escolares que foram propostos como voz ativa nos destinos administrativos e pedagógicos das escolas, estão reduzidos a entes burocráticos de fiscalização de contas e balanços financeiros. ${ }^{14}$

Como mais à frente se verá, ressalvando as especificidades, algo semelhante se passa em Portugal. Com efeito, o órgão que está no topo do organograma de qualquer agrupamento de escolas ou escola não agrupada é o órgão designado Conselho Geral (onde estão os representantes da comunidade educativa), mas esse órgão colegial (principal reduto da democracia escolar) nem sempre exerce, ou exerce de forma muito mitigada, as funções que the estão legalmente atribuídas como órgão de "direção-estratégica", acabando, frequentemente, por endossar ou legitimar muitas das propostas ou decisões do órgão unipessoal de gestão (diretor). Esse fato reforça a centralidade do diretor na vida quotidiana dos agrupamentos de escolas, esvaziando de conteúdo expressivo ou despolitizando o Conselho Geral enquanto órgão colegial que

14 E acrescenta: "Os diretores eleitos, após embates históricos pela democratização da escolha dos dirigentes escolares, estão atulhados de compromissos com programas oficiais de avaliação, de medidas, de índices, e sendo forçados a firmar contratos de gestão com as secretarias de educação (HYPOLITO, 201 l, p. 72). No caso português, essa azáfama gerencialista passa também pela omnipresença das plataformas informáticas que ligam as escolas e os Agrupamentos de escolas ao Ministério da Educação, que os tutela. A exigência de inserção frequente de relatórios, informações, dados estatísticos, entre muitas outras solicitações, tornou as plataformas informáticas um exemplo paradigmático de hiperburocratização do trabalho dos professores e dos gestores (diretores). Como a esse propósito salienta Lima (201 l, p. 18): "[...] visível nas escolas portuguesas, - exagero dos traços da burocracia weberiana resulta numa burocracia escolar radicalizada, ampliada, ou, como prefiro chamar-lhe, numa hiperburocracia, aliás induzida e reforçada pelas novas tecnologias da informação e comunicação, que emergem como uma espécie de nova fonte de controlo centralizado, eletrónico e aparentemente difuso, mas contudo poderoso, sempre presente em cada momento e em todos os lugares, isto é, de natureza totalizante e, por vezes, quase totalitária." 
deveria assumir uma efetiva direção democrática e ser o local mais importante de expressão e de negociação (política) dos diferentes interesses internos e externos.

\section{O DIRETOR ESCOLAR (GESTOR) ENTRE O MINISTÉRIO DA EDUCAÇÃO E O CONSELHO GERAL}

Com algumas alterações entretanto introduzidas, o "regime de autonomia, administração e gestão" que vigora atualmente em Portugal foi aprovado em $2008^{15}$ e aplica-se às escolas públicas dos ensinos básico e secundário (fundamental e médio) e aos estabelecimentos públicos de educação pré-escolar. Ao contrário do que acontecia há alguns anos, em que cada escola tinha a sua própria identidade e cultura organizacional, a maior parte das escolas e estabelecimentos de educação pré-escolar está agora integrada em agrupamentos, com dimensões diferentes conforme os anos de escolaridade que são lecionados e o número de alunos, professores, educadores e funcionários. Os agrupamentos de escolas são consequência de uma medida governativa muito polêmica, interpretada pelos setores educacionais mais críticos como tendo sido motivada essencialmente por lógicas neoliberais de eficiência, as quais se traduziram no enxugamento de recursos materiais e humanos em nível da administração e gestão e no aumento do controlo por parte do poder central.

As eventuais vantagens dos agrupamentos de escolas - que poderiam proporcionar um acompanhamento em continuidade aos alunos, desde os anos iniciais até o fim do ensino secundário (médio), ou permitir maior intercâmbio científico e pedagógico entre professores de diferentes ciclos e níveis de ensino -, têm sido obstaculizadas por razões várias, nomeadamente pela escassa disponibilidade dos profissionais para o trabalho conjunto, nomeadamente em termos de planejamento de atividades entre ciclos e anos de escolaridade diferentes, sobretudo quando estão fora dos círculos de maior proximidade

15 Trata-se do Decreto-Lei n. 75, de 22 de abril de 2008, republicado como anexo ao Decreto-Lei n. 137, de 02 de junho de 2012 . 
científico-pedagógica e geográfica. Por outro lado, apesar da existência de um projeto educativo comum, reproduzem-se em nível interno as relações centro-periferia, isto é, as escolas geograficamente mais distantes continuam pouco integradas ou, muitas vezes, continuam a sentir-se periféricas, agora em relação ao centro constituído pela escola-sede do agrupamento, onde ficam os órgãos de administração e gestão: o conselho geral, o diretor, o conselho pedagógico e o conselho administrativo. ${ }^{16}$

Para os objetivos neste texto, circunscrevemos apenas essa breve análise à função do diretor e à função do conselho geral, tendo sempre em mente que o diretor (enquanto gestor) está sujeito a uma dupla subordinação hierárquica: por um lado, ao conselho geral e, por outro, ao Ministério da Educação. Considerando a organização de uma parte do subsistema de ensino não superior português, constituído pelas escolas públicas dos ensinos básico e secundário (fundamental e médio) e estabelecimentos públicos de educação de infância, é importante sublinhar que, apesar da já longa permanência da retórica da autonomia em face do poder central, esse subsistema continua a ser (simultânea e paradoxalmente) fortemente controlado pelo Estado (por meio do Ministério da Educação e de outros serviços centrais da administração pública), embora esteja também aberto à participação da comunidade educativa, com o crescente escrutínio e controle dos múltiplos interesses (stakeholders) sociais, políticos, empresariais, jornalísticos, culturais, etc. E é justamente desse conjunto de atores que emanam pressões, demandas e expectativas (frequentemente contraditórias) que aqui traduzimos, na esteira de outros autores, como sendo uma forma de accountability múltipla.

Considerando apenas o que está formalmente legislado para as escolas públicas portuguesas, o Quadro l evidencia precisamente que é o diretor (gestor) que está no centro dessas demandas diversas que se traduzem na obrigação de uma accountability múltipla, cujo pilar mais visível, nesse caso, é a prestação de contas, que se expressa em momentos distintos e com diferentes graus de intensidade e importância. Talvez pudéssemos dizer, mais rigorosamente, que se trata de formas parcelares de accountability múltipla,

\footnotetext{
16 Para uma perspectiva crítica sobre a gênese dos agrupamentos de escolas, ver, por exemplo, Lima (2004).
} 
uma vez que o pilar da prestação de contas é o mais considerado (ainda que, muitas vezes, de forma implícita ou indireta) na referida legislação sobre a administração e gestão das escolas públicas portuguesas do ensino não superior e, portanto, aquele sobre o qual recaem pressões e expectativas mais fortes, por parte de diversos atores, na medida em que o pilar da prestação de contas implica atos de justificação, fundamentação ou argumentação relativos às práticas e decisões do diretor (gestor).

Quadro 1 - $\bigcirc$ diretor (gestor) em um contexto de accountability múltipla

\begin{tabular}{|c|c|c|c|c|c|}
\hline \multirow[b]{2}{*}{$\frac{\text { Ministério da }}{\text { Educação }}$} & \multicolumn{2}{|c|}{$\begin{array}{lll}r & r \\
1\end{array}$} & ----- & & \multirow{2}{*}{$\llbracket \begin{array}{r}1 \\
1 \\
1 \\
1 \\
1 \\
1 \\
1 \\
1\end{array}$} \\
\hline & $\begin{array}{l}\text { Conselho } \\
\text { Geral } \\
\text { (órgão de } \\
\text { direção } \\
\text { estratégica) }\end{array}$ & $\begin{array}{l}\text { Diretor } \\
\text { (órgão } \\
\text { unipessoal de } \\
\text { gestão) }\end{array}$ & $\begin{array}{c}\text { IGEC } \\
\text { (Inspeção } \\
\text { Geral de } \\
\text { Educação e } \\
\text { Ciência) }\end{array}$ & $\begin{array}{c}\text { Stakeholders } \\
\text { e outras } \\
\text { entidades }\end{array}$ & \\
\hline $\begin{array}{l}\text { Quem pede } \\
\text { contas e a } \\
\text { quem se } \\
\text { prestam } \\
\text { contas }\end{array}$ & $\begin{array}{l}\text { Quem pede } \\
\text { contas e a } \\
\text { quem se } \\
\text { prestam } \\
\text { contas }\end{array}$ & $\begin{array}{c}\text { A quem se } \\
\text { pedem contas } \\
\text { e quem presta } \\
\text { contas }\end{array}$ & $\begin{array}{l}\text { Quem pede } \\
\text { contas e a } \\
\text { quem se } \\
\text { prestam } \\
\text { contas }\end{array}$ & $\begin{array}{l}\text { Quem pede } \\
\text { contas e a } \\
\text { quem se } \\
\text { prestam } \\
\text { contas }\end{array}$ & $\begin{array}{l}\text { Avaliação } \\
\text { Externa }\end{array}$ \\
\hline
\end{tabular}

Fonte: o autor.

Isto não invalida (antes pressupõe) que, em certas situações, seja igualmente acionado o pilar da avaliação (ou da autoavaliação) e que se prevejam consequências (pilar da responsabilização), como evidencia, no Quadro 1, a relação da avaliação externa das escolas com o trabalho do diretor. Mais concretamente, como acontece com os titulares do conselho geral, do conselho pedagógico e do conselho administrativo, no exercício das suas funções, o diretor presta contas quando "responde perante a administração educativa", isto é, perante o Ministério da Educação e/ ou outros serviços centrais. Com base na legislação aqui referenciada, é o conselho geral que tem, no entanto, a competência de "eleger o diretor" e que decide a sua recondução, podendo o seu mandato cessar "em caso de manifesta desadequação da respectiva gestão, fundada em fatos comprovados e informações devidamente fundamentadas" ou, ainda, "na sequência de processo disciplinar". Por sua vez, o diretor tem de prestar contas ao conselho geral na medida em que deve facultar "todas as informações necessárias para este realizar eficazmente o 
acompanhamento e a avaliação do funcionamento do agrupamento de escolas ou escola não agrupada." (PORTUGAL, 2012a). Além disso, o conselho geral participa no processo de "avaliação do desempenho do diretor", sendo que, nesse caso, a classificação a ser atribuída considera uma componente de avaliação interna (baseada em um relatório de autoavaliação elaborado pelo diretor) e uma componente baseada nos resultados da avaliação externa do respectivo agrupamento de escolas ou escola não agrupada (Portaria n. 226, de 30 de agosto de 2012). ${ }^{17}$ (PORTUGAL, 2012b). Aliás, as questões relacionadas com a avaliação externa das escolas se tratam, sobretudo, no âmbito da interação direta dos diretores com a Inspeção-Geral da Educação e Ciência (IGEC). Ao contrário, as questões financeiras, administrativas e de gestão do pessoal docente são muito frequentemente tratadas nos contactos com outros serviços centrais do Ministério da Educação, podendo ser interpretadas como "verdadeiramente nucleares no que diz respeito às dimensões burocrática e política da organização escolar." (LIMA; SÁ; SILVA, 2017, p. 225). Isto não significa, no entanto, que não possa haver "alguma ambivalência no relacionamento entre as duas partes" (LIMA; SÁ; SILVA, 2017. p. 226) - questão, aliás, muito relevante, para a qual a continuidade deste último trabalho de pesquisa certamente aprofundará (ver Lima e Sá (2017)).

Essa ambivalência, todavia, não se circunscreve às relações do diretor com os serviços centrais do Ministério da Educação. Se, como atrás sinalizamos, considerarmos a existência de dilemas e tensões decorrentes das diversas pressões e expectativas, internas e externas, advindas de uma pluralidade de atores (individuais e coletivos) - que se traduzem, do nosso ponto de vista, na própria gestão de formas parcelares de accountability múltipla, nas quais o diretor tem grande centralidade -, não parece improvável que muitas outras ambivalências (e mesmo resistências) tenham de ser melhor compreendidas, sobretudo se quisermos inscrever a pesquisa no âmbito de uma sociologia das organizações educativas.

\footnotetext{
17 Tendo os resultados da avaliação externa do agrupamento de escolas ou escola não agrupada um peso de 40\% na classificação de desempenho do gestor (diretor), não surpreende que este se envolva fortemente na preparação da escola para a avaliação externa, que é realizada pela Inspeção-Geral da Educação e Ciência (a esse propósito, ver, por exemplo, Inspeção-Geral da Educação e Ciência (2016)).
} 


\section{REFERÊNCIAS}

AFONSO, A. J. Avaliar a escola e a gestão escolar: elementos para uma reflexão crítica. In: ESTEBAN, T. (Org.). Escola, currículo e avaliação. São Paulo: Cortez, 2003. p. 38-56.

AFONSO, A. J. Gestão, autonomia e accountability na escola pública portuguesa: breve diacronia. Revista Brasileira de Política e Administração da Educação, Goiânia, v. 26, n. 1, p. 13-30, jan./abr. 2010.

AFONSO, A. J. Neomeritocracia e novas desigualdades - breves comentários. In: TORRES, L. L.; PALHARES, J. A. (Org.). A excelência na escola pública portuguesa. V. N. de Gaia: Fundação Manuel Leão, 2017. p. 253-263.

AFONSO, A. J. O novo modelo de gestão das escolas e a conexão tardia à ideologia neoliberal. Revista Portuguesa de Educação, Braga, v. 8, n. 1, p. 73-86, 1995.

AFONSO, N. A direção das escolas públicas em Portugal: dinâmicas do contexto e lógicas de acção dos gestores escolares. In: BARZANÒ, G. (Org.). Culturas de liderança e lógicas de responsabilidade: as experiências de Inglaterra, Itália e Portugal. V. N. Gaia: Fundação Manuel Leão, 2009. p. 1525.

ALMEIDA, A. N. et al. Gestão e financiamento das escolas em Portugal. Indicadores, Políticas e Atores. Lisboa: Fundação Calouste Gulbenkian, 2017.

ANTUNES, F; PERONI, V. Reformas do Estado e políticas públicas: trajetórias de democratização e privatização em educação. Brasil e Portugal, um diálogo entre pesquisas. Revista Portuguesa de Educação, Braga, v. 30, n. 1, p. 181216, 2017.

ANTUNES, F. Políticas, processos e atores de privatização da educação em Portugal: apontamentos. In: PERONI, V. (Org.). Diálogos sobre as redefinições no papel do Estado e nas fronteiras entre o público e o privado na educação. São Leopoldo: Oikos, 2015. p. 129-143. 
BARZANÒ, G. Culturas de liderança e lógicas de responsabilidade: as experiências de Inglaterra, Itália e Portugal. V. N. Gaia: Fundação Manuel Leão, 2009.

BARZANÒ, G. School autonomy and the new 'accountabilities' of European education leaders: case studies in England, France, Italy and Portugal. Italian Journal of Sociology of Education, Roma, i. 3, p. 184-209, 2011.

BOLTANSKI, L.; CHIAPELLO, E. El Nuevo Espíritu del Capitalismo. Madrid: Akal, 2002.

BROWN, P. The 'third wave': education and the ideology of parentocracy. British Journal of Sociology of Education, London, v. 1 1, i. 1, p. 65-86, 1990.

CLARKE, J.; NEWMAN, J. The right to manage: a second managerial revolution? Cultural Studies, London, v. 7, i. 3, p. 427-441, 1993.

HYPOLITO, Á. M. Reorganização gerencialista da escola e trabalho docente.

Educação: Teoria e Prática, Goiânia, v. 21, n. 38, p. 59-78, out./dez. 2011.

INSPEÇÃO-GERAL DA EDUCAÇÃO E CIÊNCIA. Avaliação Externa das Escolas 2013-2014 - Relatório. Lisboa: IGEC, 2016. Disponível em: < http:// www.ige.min-edu.pt/upload/Relatorios/AEE_2013-2014_RELATORIO.pdf > . Acesso em: 11 maio 2018.

JANTZ, B.; JANN, W. Mapping accountability changes in labour market administrations: from concentrated to shared accountability? International Review of Administrative Sciences, v. 79, i. 2, p. 227-248, 2013.

KNAPP, M. S.; FELDMAN, S. B. Managing the intersection of internal and external accountability. Challenge for urban school leadership in the United States. Journal of Educational Administration, v. 50, i. 5, p. 666-694, 2012.

KOYAMA, J. Principals as bricoleurs: making sense and making do in an era of accountability. Educational Administration Quarterly, v. 50, i. 2, p. 279-304, 2014.

LIMA, L. C. A gestão democrática das escolas: do autogoverno à ascensão de uma pós-democracia gestionária? Educação e Sociedade, Campinas, v. 35, n. 129, p. 1067-1083, out./dez. 2014.

LIMA, L. C. Aprender para ganhar, conhecer para competir. São Paulo: Cortez, 2012. 
LIMA, L. C. O agrupamento de escolas como novo escalão da administração desconcentrada. Revista Portuguesa de Educação, Braga, v. 17, n. 2, p. 7-47, 2004.

LIMA, L. C. Políticas educacionais, organização escolar e trabalho dos professores. Educação: Teoria e Prática, v. 21, n. 38, p. 8-26, out./dez. 2011.

LIMA, L. C. Por que é tão difícil democratizar a gestão da escola pública? Educar em Revista, Curitiba, v. 34, n. 68, p. 15-28, mar./abr. 2018a.

LIMA, L. C. Privatização lato sensu e impregnação empresarial na gestão da educação pública. Currículo sem Fronteiras, v. 18, n. 1, p. 128-144, jan./ abr. $2018 b$.

LIMA, L. C.; SÁ, V. (Org.). O Governo das Escolas. Democracia, controlo e performatividade. V. N. Famalicão: Húmus, 2017.

LIMA, L. C.; SÁ, V.; SILVA, G. R. O que é democracia na 'gestão democrática das escolas'? In: LIMA, L. C.; SÁ, V. (Org.). O Governo das Escolas. Democracia, controlo e performatividade. V. N. Famalicão: Húmus, 2017. p. 213-258.

MARKS, H. M.; NANCE, J. P. Contexts of accountability under systemic reform: implications for principal influence on instruction and supervision. Educational Administration Quarterly, v. 43, i. 1, p. 3-37, 2007.

MARTINS, E. M.; KRAWCZYK, N. R. Estratégias e incidência empresarial na atual política educacional brasileira: o caso do movimento 'Todos Pela Educação'. Revista Portuguesa de Educação, Braga, v. 31, n. 1, p. 4-20, 2018.

MARTINS, E. M. Todos pela Educação? Como os empresários estão determinando a política educacional brasileira. Rio de Janeiro: Lamparina, 2016.

MENDONÇA, M. Novo regime é um retrocesso no funcionamento democrático da escola pública. A Página da Educação, v. 2, n. 186, p. 36-39, 2009.

NEWMAN, J.; CLARKE, J. Gerencialismo. Educação e Realidade, Porto Alegre, v. 37, n. 2, p. 353-381, maio/ago. 2012.

PARO, V. H. Escritos sobre Educação. São Paulo: Xamã, 2001.

PERONI, V. Múltiplas formas de materialização do privado na educação básica pública no Brasil: sujeitos e conteúdo da proposta. Currículo sem Fronteiras, v. 18, n. 1, p. 212-238, jan./abr. 2018. 
POLLOCK, K.; WINTON, S. Juggling multiple accountability systems: how three principals manage these tensions in Ontario, Canada. Educational Assessment, Evaluation and Accountability, v. 28, i. 4, p. 323-345, 2016.

PORTUGAL. Decreto-Lei n. 75, de 2008. Republicado em anexo ao Decreto-Lei n. 137, de 02 de junho de 2012. Diário da República, Lisboa, 02 jul. $2012 \mathrm{a}$.

PORTUGAL. Portaria n. 226, de 30 de agosto de 2012. Diário da República, Lisboa, 30 ago. 2012b.

SCHILLEMANS, T. Managing public accountability: how public managers manage public accountability. International Journal of Public Administration, i. 38, p. 433-441, 2015.

TORRES, L. L. Liderança singular na escola plural: as culturas da escola perante o processo de avaliação externa. Revista Lusófona de Educação, Lisboa, n. 23, p. 51-76, 2013.

Recebido em 19 de junho de 2018 Aceito em 25 de julho de 2018

Endereços para correspondência: Universidade do Minho, Instituto de Educação, Campus de Gualtar, 4715-123, Braga, Portugal; ajafonso@ie.uminho.pt 